\title{
A comercialização da contracepção de emergência em drogaria do município do Rio de Janeiro: aspectos éticos e metodológicos de uma pesquisa etnográfica commercialization of emergency contraception in a drugstore in the city of Rio de Janeiro: ethical and methodological aspects of an ethnographic research
}

\author{
Sabrina Pereira Paiva \\ Doutora em Saúde Coletiva. Professora na Faculdade de Ciências \\ Médicas e da Saúde de Juiz de Fora. \\ E-mail: sabrinappaiva®gmail.com \\ Elaine Reis Brandão \\ Professora adjunta da Universidade Federal do Rio de Janeiro/ \\ Departamento de Medicina Preventiva e Instituto de Estudos em \\ Saúde Coletiva. \\ E-mail: brandao®iesc.ufrj.br

\section{Correspondência} \\ Sabrina Pereira Paiva \\ Rua Isabel Corrêa de Souza, 60, São Pedro, CEP 36037-050, Juiz \\ de Fora, MG, Brasil.
}

\section{Resumo}

O artigo discute aspectos éticos e metodológicos relativos à pesquisa etnográfica em drogaria da Zona Norte do município do Rio de Janeiro, no período 2011-2012. Buscou-se conhecer a dinâmica de provisão da contracepção de emergência pela drogaria, bem como a interação social entre o/a vendedor/a e/ou farmacêutico/a e o/a consumidor/a no ato da compra da pílula. A investigação está permeada por desafios relacionados ao caráter comercial das drogarias no país, embora estes estabelecimentos sejam considerados legalmente "de interesse para a saúde". No primeiro momento, apresenta-se a discussão sobre os antecedentes do trabalho de campo: a busca pela aprovação da pesquisa tanto pelo Comitê de Ética em Pesquisa quanto por proprietários de drogarias. Em seguida, o processo de entrada em campo é problematizado pela perspectiva das relações e posições assumidas pela pesquisadora e sujeitos pesquisados. A opção pela etnografia no contexto privado das drogarias, visando conhecer a comercialização da contracepção de emergência, foi fundamental para a compreensão de processos complexos relacionados aos jogos sutis de controle da sexualidade e reprodução nesse espaço. A interação entre pesquisadora e sujeitos da pesquisa em campo é um processo socialmente construído, conforme as circunstâncias específicas que demarcam a coleta de dados/pesquisa, por isso o método da pesquisa e a postura ética precisam estar bem definidos e 
claros para o pesquisador. Ambos estão interligados, dependem do exercício criativo e da avaliação crítica do pesquisador sobre suas relações em campo.

Palavras-chave: Etnografia; Contracepção de emergência; Farmácia; Ética; Metodologia de pesquisa.

\section{Abstract}

This article discusses ethical and methodological aspects related to the ethnographic research conducted in a drugstore in the city of Rio de Janeiro, Brazil, in 2011 and 2012. The aim was analyzing the dynamics of emergency contraception commercialization by this drugstore, as well as the social interaction between the seller and/or pharmacist and the customer at the time the latter purchases the pill. The investigation is permeated by challenges related to the commercial nature of drugstores in the country, even though these commercial establishments are legally considered as having a "health-related interest”. First, we introduce a discussion on the background of the fieldwork: the quest for research approval, both by the research ethics committee concerned and by drugstore owners. Then, the process of getting into the field is discussed from the perspective of the relations and positions taken by the female researcher and the subjects under analysis. The choice for ethnography in the private context of drugstores, aiming to identify the commercialization of emergency contraception, was crucial to apprehend the complex processes related to the subtle games of sexuality and reproduction control in this space. The interaction between the female researcher and the research subjects during fieldwork constitutes a socially constructed process, according to the specific circumstances that delimit the collection of data/the research, thus, the research method and the ethical attitude must be properly defined and clear for the researcher. They are interconnected, depending on a creative exercise and a critical evaluation of the researcher on her/ his relations within the field.

Keywords: Ethnography; Emergency Contraception; Pharmacy; Ethics; Search Methodology. 


\section{Introdução}

A contracepção de emergência/levonorgestrel (CE), mais conhecida como "pílula do dia seguinte", é um anticoncepcional com característica diferenciada em relação a todos os outros existentes, pois deve ser ingerido no máximo até 120 horas após o ato sexual. 0 uso dessa tecnologia é indicado na prevenção de uma eventual gravidez, decorrente de falha do método contraceptivo regular, seu uso inadequado, ausência de proteção na relação sexual e violência sexual, não cabendo sua utilização como método de rotina. Nesse sentido, também pode evitar eventuais abortos inseguros, um grave problema de saúde pública em âmbito mundial (Brasil, 2011; Drezett, 2010; Leung e col., 2010).

No entanto, o fato de a CE ser utilizada após o ato sexual fez com que esse anticoncepcional passasse a ser indevidamente associado aos medicamentos abortivos, até mesmo entre profissionais de saúde responsáveis por sua prescrição e dispensação. A mídia de massa contribui para aumentar a confusão, ao misturar preocupações sobre moralidade sexual, uso inapropriado e/ou repetido da CE e medo do aumento das doenças sexualmente transmissíveis, devido ao não uso do preservativo (Souza e Brandão, 2012; Paiva e Brandão, 2012).

Salienta-se que, no contexto brasileiro, a Agência Nacional de Vigilância Sanitária (Anvisa) aprovou, em 1999, a comercialização da CE pelas drogarias sob prescrição médica ${ }^{1}$. No entanto, a venda ocorre, na maior parte das vezes, sem a apresentação de receita médica. Devido às facilidades de acesso ao método nas drogarias, principalmente nos horários noturnos e finais de semana, quando a rede básica de saúde encontra-se fechada, estes estabelecimentos tornaram-se os mais procurados por quem necessita da CE. Hoje há mais de 15 marcas deste produto disponíveis no mercado brasileiro (Figueiredo e col., 2008).
O artigo trata das dimensões éticas e metodológicas envolvidas na investigação etnográfica, realizada em drogaria da Zona Norte do município do Rio de Janeiro, na zona da Leopoldina, no período de janeiro de 2011 a dezembro de 2012. A pesquisa intencionou conhecer a dinâmica de provisão da CE às usuárias que recorrem às drogarias para adquirir o produto, bem como a interação social que se estabelece no processo de comercialização do medicamento entre o/a vendedor/a e o/a consumidor/a.

Destacam-se os desafios concernentes a essa abordagem metodológica no âmbito de drogarias privadas, ambiente que a priori parece improvável para o estabelecimento de diálogo e vínculo com os sujeitos de pesquisa: balconistas/farmacêuticos e consumidores/as. A venda de produtos farmacêuticos é a atividade prioritária para os que trabalham nesses estabelecimentos e nada deve interrompê-la, assim como a privacidade dos clientes não deve ser invadida. Além disso, a temática referente à sexualidade e contracepção, por ser considerada de foro íntimo, poderia tornar mais complexo o processo de aproximação entre consumidores e vendedores e entre pesquisadora e sujeitos de pesquisa.

Inicialmente percorrem-se os caminhos e argumentos utilizados para obtenção da aprovação da pesquisa pelo Comitê de Ética em Pesquisa (CEP) da instituição acadêmica que sedia o projeto, de acordo com as determinações constantes na resolução 196/1996 vigente à época e, em seguida, pelos proprietários das drogarias.

Sabe-se que uma das principais características da pesquisa etnográfica é a integração do observador no campo. Portanto, o segundo elemento trabalhado no artigo refere-se à relação estabelecida entre pesquisadora e funcionários/as da drogaria, orientada inicialmente pela tarefa de construção do vínculo, elemento fundamental para a pesquisa qualitativa. Buscamos a noção de reflexividade em Bourdieu (1989), visando problematizar identidades,

1 Em 2012, o Ministério da Saúde lançou o protocolo para utilização do levonorgestrel como anticoncepção de emergência, autorizando os/as enfermeiros/as da rede pública a dispensarem-no. As principais indicações são: deslocamento do diafragma; rompimento do preservativo; esquecimento prolongado do anticonceptivo oral ou atraso do injetável; coito interrompido em que ocorre derrame do sêmen na vagina; cálculo incorreto do período fértil, erro no período de abstinência ou interpretação equivocada da temperatura basal; casos de violência sexual quando a mulher ou adolescente são privadas de escolha e submetidas à gravidez indesejada; relação sexual desprotegida sem uso de nenhum método contraceptivo e preservativos (Brasil, 2012a). 
diferenças e posições assumidas pela pesquisadora e seus sujeitos de investigação, enfocando os momentos iniciais das relações estabelecidas em campo e caracterizando sua importância para o decorrer da etnografia.

Pretende-se evidenciar no decorrer do texto a complexidade do trabalho de campo, exibindo a inadequação das normas e regras como determinantes da ética e, ao mesmo tempo, demonstrando as estratégias metodológicas utilizadas pela pesquisadora nas situações concretas de investigação.

\section{A drogaria como cenário etnográfico: reflexões éticas e metodológicas}

\section{Antecedentes do trabalho de campo I: aspectos éticos e metodológicos}

Schmidt (2008) observa que o trabalho de campo, como experiência prática pessoal e intransferível, exibe de modo mais decisivo a impossibilidade das normas e regras per se serem determinantes da ética, assim como revela a necessidade do método ser maleável, podendo ser reinventado nas situações concretas de investigação. Nessa mesma direção, ressalta-se que a pesquisa etnográfica é uma experiência compreensiva que envolve a totalidade da pessoa, o que torna mais difícil apresentar uma metodologia articulada em torno de passos específicos a serem seguidos, visando assegurar um produto final (Giumbelli, 2002).

Os pesquisadores sociais, em geral, quando chegam ao local para realizar sua investigação, apresentam seus estudos sem muitos detalhes. Busca-se fornecer um panorama geral e espera-se que várias outras questões emerjam do campo, até mesmo associações inesperadas não previstas. A Comissão Nacional de Ética em Pesquisa (Conep), ao contrário, seguindo a matriz de pesquisas médicas clínicas e experimentais, estabelece que os pesquisadores devem informar os detalhes da pesquisa a todos os sujeitos que dela participem, como entrevistados ou não, antes da fase de coleta de dados (Heilborn, 2004).

De acordo com a resolução 196/96, vigente à época da investigação ${ }^{2}$, o passo inicial do estabelecimento de contato com o sujeito pesquisado é a leitura e assinatura do Termo de Consentimento Livre e Esclarecido (TCLE), que deve conter todos os aspectos referentes aos objetivos, às hipóteses, aos métodos, riscos, benefícios e às questões referentes ao anonimato e sigilo dos sujeitos da pesquisa (Brasil, 1996). Ressalta-se que esse instrumento é valioso, expressando o direito do sujeito pesquisado de obter informações precisas sobre o pesquisador, sua localização no espaço social e a quem se destina a pesquisa.

Apesar da popularidade do TCLE no campo das ciências médicas, ele foi criticado de forma generalizada pelos pesquisadores de ciências sociais e humanas, em particular aqueles que trabalham no campo das humanidades em saúde. Uma relação inicial mal estabelecida na pesquisa de cunho etnográfico pode inviabilizar a sua continuidade ou provocar bias de conveniência social por parte dos sujeitos observados. Significa que estes podem, tendo domínio pormenorizado dos interesses do pesquisador, manipular e controlar as suas impressões, ou seja, alterar de forma significativa o contexto etnografado (Berreman, 1975; Knauth, 2010).

No espaço das drogarias privadas, que se configuram como locais de curta permanência para os consumidores, avaliou-se como inoportuna a assinatura individual do TCLE por todos aqueles que circulam em seu interior e são objeto de observação, de acordo com os objetivos da pesquisa: os consumidores, os representantes de laboratórios, os funcionários do telemarketing, balconistas, farmacêuticos, gerentes, embaladoras, perfumistas, operadores de caixas, proprietário etc.

Considerou-se inconveniente a entrada em campo por meio desse documento que prevê auto-

2 Em 12 de dezembro de 2012, o Conselho Nacional de Saúde instituiu a Resolução n. 466, que substituiu a 196/1996 na regulamentação das diretrizes e normas éticas referentes às pesquisas envolvendo seres humanos no Brasil. No que se refere aos aspectos particulares das investigações em ciências sociais e humanas tratados neste artigo, a nova resolução não traz novidades. Mas, afirma-se que as especificidades éticas das pesquisas nas ciências sociais e humanas serão contempladas em resolução complementar, dadas suas peculiaridades (Brasil, 2012b). 
rização por escrito, pois tal procedimento poderia assustá-los, principalmente devido ao ineditismo da pesquisa nesse contexto e por conta do temor que o setor possui em relação à fiscalização dos órgãos reguladores do Estado. A saída encontrada foi a abordagem face a face para esclarecimento dos principais aspectos da investigação, além daqueles relativos ao anonimato e sigilo, com indagação verbal sobre a concordância em participar da mesma. 0 TCLE foi utilizado de modo formal somente com os sujeitos que seriam entrevistados individualmente. Neste caso, os/as funcionários/as da drogaria.

E quanto à participação dos/as consumidores/ as? Como poderia se dar essa relação? Levando em consideração que a sua passagem pela drogaria é fortuita e que a compra da CE envolve urgência, optou-se por garantir sua participação através de um questionário fechado, auto preenchível e de urna, com isenção do TCLE nos moldes clássicos. Tal opção justificou-se pela importância da informação a ser colhida na pesquisa e a absoluta garantia do anonimato, indispensável nos estudos que envolvem temas sensíveis e muito íntimos (Diniz e Medeiros, 2010).

Além disso, entre os/as consumidores/as, os/as jovens menores de 18 anos conformam parte importante do público consumidor da CE, considerando-se fundamental conhecer as circunstâncias em que estão consumindo tal medicamento, com que periodicidade e como adquiriram informações a respeito. Sabe-se que a Resolução 196/96 estabelece a obrigatoriedade da assinatura do TCLE pelos pais ou responsáveis legais desses jovens. Porém, a garantia de confidencialidade e privacidade aos sujeitos adolescentes, de acordo com Guariglia e colaboradores (2006), seguindo diretrizes internacionais, prevê o consentimento autônomo para o/a adolescente, sem pedir autorização dos pais, em determinados casos em que esta exigência possa inviabilizar a pesquisa.

Ponderando-se riscos e benefícios, entendeu-se que a exigência de assinatura do TCLE pelos pais ou responsáveis poderia tornar essa população vulnerável ao invés de protegê-la, já que é sabido que esta adquire métodos contraceptivos, na maior parte das vezes, sem anuência desses, dificultando ou impedindo sua participação na pesquisa (Ventura, 2009; Rogers e Ballantyne, 2008).
O processo de diálogo com o Comitê de Ética em Pesquisa da instituição acadêmica foi produtivo, à medida que incitou o debate no interior do grupo de pesquisa e do próprio CEP a respeito de premissas éticas previamente estabelecidas, mas que podem ser flexíveis, desde que se mantenha o compromisso com o bem-estar e livre-arbítrio dos sujeitos da pesquisa em sua totalidade. A pesquisa foi aprovada pelo CEP do Instituto de Estudos em Saúde Coletiva da Universidade Federal do Rio de Janeiro, sob protocolo n. 1/2012.

\section{Antecedentes do trabalho de campo II: em busca das drogarias}

As drogarias no Brasil são estabelecimentos caracterizados legalmente como de "interesse para a saúde”, responsáveis pela dispensação e comércio de drogas, medicamentos, insumos farmacêuticos e correlatos em suas embalagens originais (Brasil, 1973). Tais estabelecimentos têm o dever legal de garantir e zelar pela manutenção da qualidade e segurança dos produtos ofertados, bem como pelo uso racional de medicamentos, a fim de evitar riscos e efeitos nocivos à saúde, conforme disposto na Resolução da Diretoria Colegiada n. 44/2009 (RDC n. 44/2009), da Anvisa, que dispõe sobre as boas práticas farmacêuticas (Brasil, 2009).

Contudo, na prática, percebe-se que, em nosso país e em outros contextos, esses estabelecimentos voltam-se fortemente para o mercado, tendo como fim último de sua atividade a venda de produtos farmacêuticos e não a prestação de atendimentos e informações para o uso correto e racional de medicamentos. Ressalta-se que a intensificação do processo de medicalização social, que culmina no que alguns autores denominam de "farmaceuticalização da sociedade", transformou as farmácias e drogarias em disputados mercados, com poderes e lucros crescentes. Essa engrenagem necessita, para seu funcionamento, do estímulo constante ao consumo de medicamentos, estejam ou não os indivíduos sofrendo de algum transtorno ou doença (Nascimento, 2005; Bastos e Caetano, 2010; Conrad, 2007; Williams e col., 2011).

Determinadas forças sociais no país, entre elas os conselhos profissionais de farmácia e a Anvisa, mobilizam-se na regulação das farmácias e droga- 
rias como "estabelecimentos de saúde". Defendem que os produtos ali comercializados influenciam diretamente na saúde da população e que os medicamentos não são simples mercadorias (Farina e Romano-Lieber, 2009; Oliveira e col., 2005).

No caso do comércio da CE, um número cada vez maior de países, desenvolvidos e em desenvolvimento, interessados em reduzir as taxas de gestações adolescentes e de gestações imprevistas, ao mesmo tempo estimulados pelo interesse em reduzir gastos com seguro saúde, estão aderindo crescentemente à política de dispensação da contracepção de emergência over-the-counter (OTC), isto é, do lado de "fora do balcão". De acordo com Wynn e Foster (2012), em 2010 já havia 152 países com produtos registrados para a CE, dos quais 60 já permitiam a dispensação do produto via farmácias/drogarias sem prescrição médica. Além disso, já havia mais de 100 marcas de CE disponíveis no mercado mundial.

Como nos mostra Fainzang (2012), na França, hoje em dia, do ponto de vista do Estado, parece ocorrer o encorajamento/incitação à prática da “automedicação", já que este é um meio eficaz de reduzir os encargos do seguro-doença. Isso porque os medicamentos comprados sem receita não são subsidiados pelo Estado, mas sim pelos próprios cidadãos. Mas tal prática é questionada pelos profissionais de saúde, que veem essas iniciativas como um perigo sanitário e, acima de tudo, como uma desconsideração em relação às suas competências profissionais e técnicas.

No Brasil é sabido que grande parte da população adquire o contraceptivo de emergência nas drogarias, sem receita médica, orientação e sem que tais estabelecimentos integrem quaisquer protocolos de distribuição e de comercialização dos métodos contraceptivos, no âmbito das políticas públicas de saúde, a exemplo de outros países (Paiva e Brandão, 2012).

Considerando esse contexto, inicialmente a investigação envolvia o estudo etnográfico em duas drogarias do município do Rio de Janeiro, uma na Zona Norte e outra na Sul. Tal escolha foi orientada pela "prenoção", bem estabelecida na literatura antropológica produzida na cidade, da persistência de determinada hierarquia simbólica que organiza o espaço urbano, engendrada pela oposição entre as regiões Norte e Sul (Duarte, 1986; Velho, 2008; Kuschnir, 2003).

Seguindo a argumentação de Park (1979), parte-se da percepção de que a metrópole carioca pode ser pensada a partir da interação recíproca entre sua organização física e moral. A Zona Sul nos remete à ideia de modernidade, riqueza e cosmopolitismo, enquanto à Zona Norte e aos diferentes subúrbios se atribui uma construção moral de natureza mais tradicional e, portanto, menos permeáveis aos valores modernos relativos aos indivíduos e suas construções singulares e autônomas (Heilborn, 1999).

As estratégias de aproximação com as drogarias basearam-se no contato prévio com farmacêuticos conhecidos, inseridos ou não no ramo comercial, visando sua intermediação com proprietários ou funcionários/gerentes de drogarias. A pesquisadora passou o ano de 2010 na busca das duas drogarias, estabelecendo contatos telefônicos e construindo redes de relacionamento.

De modo estratégico, a drogaria foi o local escolhido para apresentação da proposta. Além da autorização para a pesquisa, nos moldes da resolução então vigente, a 196/96, foi necessário verificar as condições de venda da CE e o perfil da população atendida no estabelecimento, tendo em vista os objetivos da investigação e o tempo disponível para o trabalho de campo. Foram visitados bairros como Ilha do Governador, Méier, Olaria, Ipanema, Catete, Laranjeiras. Nessas incursões, a pesquisadora conheceu gerentes, farmacêuticos, balconistas, representantes de laboratório e outros profissionais do ramo, drogarias pequenas e grandes, independentes e franqueadas.

Pouco a pouco, ela foi se surpreendendo com as diferenças e desigualdades observadas entre drogarias das zonas Norte e Sul do Rio de Janeiro, e obviamente com as grandes disparidades sociais presentes entre e nos cenários visitados. A estratégia de aproximação com o meio foi pensada considerando outra "prenoção": o presumido temor que os profissionais desse ramo de atividade mantêm com relação à fiscalização sanitária pública, especialmente devido ao debate relativo ao uso racional de medicamentos. Por isso, durante as tentativas de entrada em campo, optou-se por colocar o foco sobre os/as consumidores/as da CE, evitando provocar um 
clima de fiscalização sobre o trabalho desenvolvido nas drogarias.

A partir das referências oferecidas por uma farmacêutica, houve o primeiro contato com o gerente distrital de uma rede de drogarias conhecida na cidade. No momento inicial da conversa, por telefone, ele pareceu disposto a colaborar, mas logo mudou de ideia alegando que não seria aprovado pelos superiores, temendo que a investigação pudesse comprometer a privacidade dos clientes e pelo fato de ser algo inovador, fora do protocolo da empresa.

Desde o princípio, foi possível observar as diferenças entre as drogarias de rede e as independentes, como o fato das primeiras trabalharem com preços menores, tornando-se mais competitivas no mercado, dificultando a sobrevivência daquelas que se denominam "independentes", por não trabalharem com franquias. Outra questão apontada pelos sujeitos contatados é que as drogarias de rede são regidas por normas mais rígidas, visando obter o melhor resultado em termos de vendas. Estimula-se a competição intra e interdrogarias. Já as drogarias independentes são geralmente empresas familiares, nas quais o proprietário muitas vezes é o próprio farmacêutico, administrando um ou mais estabelecimentos.

A segunda tentativa ocorreu em drogaria independente, localizada na Ilha do Governador, bairro da Zona Norte do Rio de Janeiro. Nesse caso, foi agendado um encontro pessoal com a farmacêutica responsável e com um dos proprietários do estabelecimento, sendo possível prever uma abertura maior para a pesquisa. Porém, a visita revelou a inadequação da drogaria aos objetivos da investigação, por sua localização no final do bairro, em local de pouco movimento. De acordo com a farmacêutica, a procura por CE é também pouco expressiva.

Chegamos à terceira indicação da farmacêutica, o proprietário de outra drogaria privada do Méier, bairro localizado na mesma região. 0 contato foi realizado com sua filha, também farmacêutica. Posteriormente, foi agendada reunião. Entretanto, com a chegada ao local, observou-se que a família havia mudado de ramo, tendo vendido a drogaria privada e aberto uma farmácia de manipulação, devido às dificuldades de competição com as redes de drogarias que, segundo a informante da pesquisadora, atualmente dominam o mercado. Apesar disso, o encontro com a farmacêutica foi fundamental.

Por conta da antiga amizade com a colega que a havia indicado e mútua empatia no processo de apresentação da pesquisa, os proprietários da farmácia de manipulação demonstraram interesse em ajudar na apresentação da proposta para outros proprietários de drogarias conhecidos. 0 farmacêutico, pai da jovem contatada, atuava como consultor em várias drogarias do Rio de Janeiro. Assim, ele estabeleceu contato com duas outras drogarias de rede, nas zonas Norte e Sul da cidade.

No caso da drogaria da Zona Sul, a pesquisadora foi encaminhada ao estabelecimento, localizado no bairro do Catete, em uma das principais avenidas do bairro, para conversar com o farmacêutico. Logo ao chegar, ela encontrou o farmacêutico no balcão. Porém, ele não havia sido informado da pesquisa. Foram deixadas cópias do resumo da pesquisa e o compromisso de retornar na semana seguinte.

Assim, ela foi encaminhada para o escritório de recepção dos vendedores de medicamentos. Lá, explicou a proposta da investigação a outro funcionário, pedindo para falar com o proprietário e verificar a possibilidade da pesquisa ser realizada em uma das drogarias da rede. A pesquisadora citou o contato do farmacêutico, mas este não foi muito útil. Por fim, solicitou um tempo de duas semanas para conversar com o proprietário e responder.

Ao voltar no prazo estabelecido, não obteve sucesso. Nesse mesmo dia, ele ligou e solicitou maiores esclarecimentos sobre a proposta. Diante da resposta da pesquisadora, retrucou: Mas logo esse medicamento?. E também levantou a questão da privacidade do/a consumidor/a.

Em seguida, a pesquisa concentrou-se na drogaria da Zona Norte do Rio de Janeiro, igualmente sugerida pelo farmacêutico. Nesse caso, a recepção foi diferente desde o princípio. Com reunião agen-

\footnotetext{
3 A CE mais vendida nesta drogaria é fabricada pelo laboratório Cifarma, Poslov ${ }^{\circledast}$, devido ao fato de sua bonificação ser mais vantajosa tanto para o proprietário quanto para os funcionários.
} 
dada com a farmacêutica, a pesquisadora chegou à drogaria, localizada na zona da Leopoldina. 0 estabelecimento é considerado o maior da região, sendo muito frequentado e com venda de CE em larga escala, segundo funcionários. ${ }^{3}$ A conversa inicial foi amistosa e, mesmo antes da apresentação da investigação, a farmacêutica comentou sobre a concordância do proprietário com a pesquisa. Assim, definiu-se que ela seria o lócus inicial da pesquisa etnográfica, com um período exploratório de campo para amadurecimento dos objetivos e avaliação de sua viabilidade.

Além das drogarias citadas, foram visitadas outras duas na Zona Sul para verificar suas possibilidades, com apoio de outra farmacêutica. Uma, em Ipanema, bem próxima à orla, negou a participação pelo incômodo que poderia ocasionar aos clientes. A farmacêutica do local alegou que a pesquisa não tinha viabilidade naquele contexto e, muito menos, naquele endereço da rede. A outra, localizada em Laranjeiras, também considerou inviável a investigação em razão da venda inexpressiva do medicamento, por ser uma pequena drogaria, localizada em área estritamente residencial do bairro.

Assim, optou-se pela entrada em campo na Zona Norte mas sem desistir da busca por drogarias que abrigassem esta investigação na Zona Sul da cidade.

\section{Uma etnógrafa em drogaria: identidades e diferenças entre pesquisadora e sujeitos pesquisados}

Rostagnol (2011) considera especialmente valioso analisar o início do trabalho de campo, já que o mesmo encerra um volume de informações muito grande, sobretudo em relação ao que os sujeitos pensam de nós, pesquisadores. Tendo em vista que cada grupo fabrica a imagem do pesquisador a partir de seus próprios sistemas de valores, conhecer a imagem do investigador feita pelo grupo se constitui uma valiosa ferramenta de análise para decifrar o universo estudado. De outro modo, percebendo o trabalho de campo como um processo reflexivo, pessoal, à medida que parte de uma análise detalhada e profunda produzida primordialmente por um único pesquisador em campo, deve-se considerar também o próprio pesquisador e seus interesses como ferramentas do processo de produção do conhecimento (Geertz, 2005; Hoonaard, 2008).

No primeiro dia de trabalho de campo, a pesquisadora sentia um misto de ansiedade, medo e curiosidade, que poderia estar relacionado ao fato de ser sua primeira experiência com etnografias. Além da ansiedade por penetrar em um território desconhecido, havia também o receio quanto à região em que estava penetrando no Rio de Janeiro. Para os mineiros, a cidade toda é perigosa, mas a Zona Norte é cercada de "mitos" sobre a violência, tanto da polícia quanto dos "criminosos".

A drogaria fica em um vale cercado pelas comunidades que compõem o Complexo do Alemão. A população do bairro, registrada no último censo demográfico do Instituto Pereira Passos (Rio de Janeiro (município), 2010), está em torno de 58 mil habitantes, com predominância das faixas etárias entre 20 e 59 anos, que corresponde a $57 \%$ da população. Os jovens adolescentes representam 10,5\% da população. Apesar de não ser a primeira ida da pesquisadora ao bairro, naquele momento o processo foi diferente. Ela observou um grande movimento próximo à drogaria, gerados pelos bares, restaurantes e outras lojas, uma praça e uma escola pública bem próxima.

Trata-se de uma drogaria de rede em expansão, que compete com as grandes franquias presentes no território. 0 estabelecimento funciona de 8 às 22 horas diariamente, com plantões noturnos nos fins de semana, contando com aproximadamente 40 funcionários.

Quando chegou ao local, indagou os funcionários do balcão sobre a farmacêutica; eles informaram que ela já estava chegando. Enquanto esperava, observou que o formato da drogaria parecia, à primeira vista, relativamente homogêneo em relação a outros estabelecimentos farmacêuticos. Tudo muito próximo ao que é possível encontrar em qualquer região da cidade ou drogaria de rede. Funcionários uniformizados, com os homens usando camisa amarela e calça preta, sapatos fechados, os cabelos e barbas muito bem feitos, cortados rentes à pele, e as mulheres com a mesma cor de blusa, calça e avental azul, cabelos presos num coque, maquiagem e unhas feitas. 
Assim que a farmacêutica chegou, levou a pesquisadora para o interior da drogaria, e logo perguntou como gostaria de encaminhar a pesquisa. De modo bem informal e geral, a pesquisadora explicou os objetivos delimitados e a proposta metodológica. Após uma breve conversa, que esperava-se fosse bem mais longa, ocorreu o momento da apresentação individual da pesquisa para todos os balconistas e funcionários e solicitação de sua colaboração e participação. Foi um momento desafiador, já que era horário de grande movimento na drogaria e a pesquisadora não previu que a farmacêutica encaminharia o processo daquela forma. A pesquisadora conversou com os balconistas inicialmente, apresentando o projeto muito brevemente para que tivessem ciência dos objetivos da pesquisa. Foram todos amistosos, porém ficaram ansiosos para saber o papel deles.

Ficou acordado que eles poderiam avisar a pesquisadora, com os olhos, quando algum/a cliente solicitasse a CE, sem chamar sua atenção. A pesquisadora, por sua vez, comprometeu-se a abordar o/a cliente após a compra do anticoncepcional, evitando constrangê-lo/a e/ou dificultar a venda do contraceptivo. Como salientado antes, presumiam-se maiores dificuldades no contato com os/as consumidores/ as da CE naquele contexto, por isso foi utilizado somente o questionário de urna, autopreenchível e com isenção do TCLE.

Durante a explicação da pesquisa para os/as funcionários/as, apenas um dos balconistas mostrou-se menos disposto a colaborar; mais velho que os demais, também parecia mais atarefado. Enquanto a pesquisadora explicava, ele levantou os olhos e disse: Acho que você vai ter dificuldades. Sua pesquisa vai ser complicada. Questionado sobre o motivo da sua avaliação, ele explicou que as pessoas que vão comprar o medicamento sentem vergonha: Vão pelo cantinho, ficam olhando as gôndolas até ficar mais vazio. A pesquisadora concordou com a cabeça e ele disse, em seguida, que a ajudaria. Nesse momento, sentiu-se aliviada, pois temia uma resistência aberta logo de início.
Ela optou por se posicionar mais próximo do balcão, para facilitar a observação da venda da CE, o que acabou gerando maior possibilidade de diálogo com os balconistas, todos homens. Esse foi um dos aspectos de estranhamento no início do trabalho de campo, pois só havia balconistas do sexo masculino e perfumistas do sexo feminino. A organização do trabalho naquela drogaria pareceu fundada em uma lógica hierárquica de gênero, com uma divisão sexual do trabalho. A pesquisadora começou a se questionar se essa característica era cultivada intencionalmente ou não no processo de gestão do trabalho daquele estabelecimento ${ }^{4}$.

Com o tempo foi possível perceber que essa divisão sexual do trabalho não era ocasional, mas implementada de forma consciente pelo proprietário e gerentes da drogaria. 0 seu estranhamento a essa divisão do trabalho, contudo, não encontrou eco na experiência desses trabalhadores, tanto homens quanto mulheres.

A pesquisadora percebeu que, naquele contexto, mesmo com dificuldades adicionais pelo fato de serem homens e ela mulher, era fundamental que os balconistas aceitassem a pesquisa, e ela necessitava de elementos que pudessem aproximá-los para além das diferenças de gênero. Sendo assim, a origem mineira da pesquisadora se transformou, em certa medida, em um vínculo identitário, já que muitos deles migraram do mesmo Estado. Essa identidade regional os aproximou e permitiu que a relação inicial fosse permeada por curiosidades de ambos os lados, tornando-se, por isso, menos artificial e estranhada. De certo modo, tanto eles quanto ela eram "estrangeiros" na cidade, ainda que esses momentos de aproximação com a metrópole tenham ocorrido em fases muito distintas. Eles sempre puxavam assunto sobre Minas Gerais e se gabavam das conquistas realizadas na cidade maravilhosa.

Durante o trabalho de campo, os assuntos mais tratados informalmente entre os balconistas e a pesquisadora foram o futebol, os pagodes, as mulheres e o trabalho, temas centrais à sociabilidade

4 A questão da organização do trabalho sob a ótica de gênero nesta drogaria foi discutida no artigo: PAIVA, S. P.; BRANDÃO, E. R. Conversas de balcão: notas etnográficas em uma drogaria. In: FLEISCHER, S.; FERREIRA, J. (Org.). Etnografias nos serviços de saúde. Rio de Janeiro: Garamond: FAPERJ, 2014. p. 181-208. 
masculina. Percebeu-se imersa naquele terreno movediço, descrito por Sarti (2005) como característico da posição do antropólogo, de estar próxima, pela situação de pesquisa, pela familiaridade que se vai desenvolvendo e, simultaneamente, de não fazer parte daquele grupo social.

Por outro lado, eles também estranhavam a sua dedicação aos estudos, pelo fato de ser mulher e mãe e também pela pesquisa não gerar renda. A pergunta quem cuida do seu filho? veio logo. E a resposta, que incluiu a divisão de responsabilidades com o parceiro, ficou sem comentários. Certa vez, um deles a olhou diretamente e perguntou: Você é hippie?. A pesquisadora riu e fez expressão de que não tinha entendido, ele disse que era pelo seu jeito feminino diferente (jovial e descontraído), pelas suas roupas (calça jeans, tênis e blusa de malha), por não usar maquiagem.

Devagar, ela foi se tornando uma pessoa mais próxima e as razões da pesquisa foram, também por isso, tornando-se menos questionáveis. Mas, essa proximidade nunca obscureceu sua posição de "estrangeira" perante o grupo. Às vezes, o lugar de exterioridade foi útil, pois eles comentavam com ela detalhes cotidianos que não poderiam comentar com alguém de dentro. Por outro lado, se indagasse sobre algo que extrapolasse, para eles, os objetivos da pesquisa, não se sentiam seguros para responder (Foote-Whyte, 1975; Geertz, 1989).

Um momento relevante para sinalização de sua aceitação pelo grupo foi quando ficou uma semana sem comparecer à drogaria, e na semana posterior foi recebida com exaltação e alegria por todos. Um dos balconistas, que inicialmente havia reagido com rispidez, saiu do balcão e a recebeu contando eventos ocorridos no fim de semana em que ela estivera ausente. Eles comentaram sobre a venda da CE e fizeram chacota a respeito do comportamento de um dos balconistas com relação a uma cliente.

Com o tempo, a pesquisadora tornou-se um membro externo importante para o grupo, sendo chamada de conterrânea, amiga, colega, amor, e contavam sobre suas experiências de interação no balcão com as consumidoras da pílula do dia seguinte e outros medicamentos relacionados à vivência sexual, sem serem interrogados.

Na construção da sua identidade, a pesquisadora procurou não seguir a rota de uma observadora distanciada e/ou recolhida, nem ao contrário, de uma pesquisadora "afetada", mas sim de uma observadora que buscou o desempenho de papéis mais ativos e passivos, dependendo da ocasião (Favreet-Saada, 2005). Os momentos em que foi instada a desempenhar papel mais ativo relacionaram-se aos períodos de menor movimento na drogaria, quando era possível aproximar-se e conversar um pouco mais longamente com cada um dos balconistas e outros/ as funcionários/as. As conversas giravam em torno de temas trazidos por eles ou por elas. Os momentos passivos foram aqueles em que a pesquisadora se restringiu à observação dos atendimentos realizados pelos balconistas aos clientes da drogaria, em especial aos consumidores da CE.

Não havia noção exata de quanto tempo duraria o trabalho de campo, mas esta pergunta foi feita inúmeras vezes pelos interlocutores. A pesquisadora sempre deu respostas evasivas, enfatizando a necessidade de conversar com mais consumidores/ as da CE. De todo modo, sinalizou inicialmente um período de seis meses de observação, tendo em vista que o projeto inicial previa a observação em outra drogaria na Zona Sul da cidade.

Após análise preliminar do material empírico recolhido, optou-se pela permanência na drogaria da Zona Norte, visando adensar o material etnográfico, com foco sobre as práticas e interações ocorridas durante a venda da CE e outros métodos relativos às vivências sexuais e reprodutivas. Assim, o planejamento de permanecer em campo por seis meses acabou por se transformar em dois anos. Os primeiros seis meses serviram para o estabelecimento do vínculo, com realização da observação participante em dias da semana diversificados, e preparação dos outros instrumentos para coleta de dados. Esse momento inicial também foi útil para a identificação dos melhores dias e horários para observação, uma vez que o interesse estava voltado para um medicamento específico de uso emergencial.

Em seguida, a observação tornou-se mais sistemática, com visitas semanais ao campo durante seis meses, aos domingos e segundas-feiras, dias que se configuraram como os de maior venda da CE. Além disso, foram realizadas entrevistas com os balconistas e farmacêutica, mediante roteiro 
semiestruturado e contatos informais com os/as consumidores/as do contraceptivo. Após análise preliminar dos dados, a pesquisadora retornou ao campo para complementação de informações e aprofundamento de alguns aspectos fundamentais.

Enfim, considera-se que o processo lento, gradual e longo de aproximação com o ambiente e pessoas foi fundamental, já que possibilitou uma situação relacional menos rígida, ofertando maior liberdade aos sujeitos investigados, que não se sentiram a todo o momento sob o olhar da pesquisadora. Não ficou bem definido no início do campo, de forma proposital, o amplo espectro de questões passíveis de observação, o que também foi muito positivo. Aos poucos, foi possível à pesquisadora ficar mais próxima do balcão, tornando-se conhecida de consumidores frequentes, enquanto os balconistas sentiam-se seguros para conversar sobre os contextos e situações relativos aos seus processos de trabalho, suas vivências pessoais, as práticas relativas à venda da CE e o olhar sobre os/as consumidores/as do contraceptivo. As vivências em campo foram se tornando cada vez mais agradáveis, motivadas por empatias mútuas, apesar das diferenças culturais e sociais terem sempre se mantido presentes.

\section{Considerações finais}

O exercício metodológico e ético de construção desta investigação etnográfica em drogaria foi permeado por dificuldades e incertezas, mas também por surpresas e aprendizados. Foi possível observar características marcantes destas instituições e de seus personagens e avaliar as estratégias metodológicas utilizadas.

Por exemplo, a utilização da intermediação de colegas do ramo farmacêutico para aprovação dos/ as proprietários/as de drogaria funcionou melhor na Zona Norte que na Zona Sul. Nos estabelecimentos franqueados desta, a recepção da pesquisa foi atravessada pela ênfase em protocolos da empresa, que rejeitam a presença de terceiros nas drogarias. Esse foi o fator determinante para a negativa da proposta, não importando as justificativas e a prerrogativa do contato prévio com alguém conhecido. Por outro lado, a entrada da pesquisadora na Zona Norte foi determinada pelo contato do intermediário. Revela- -se, assim, a importância de problematizarmos as injunções relativas aos níveis de fechamento das instituições farmacêuticas e, consequentemente, das possibilidades de compreensão das práticas sociais realizadas em seus interiores.

Além disso, a estratégia de colocar o foco sobre os consumidores não soou positivo na Zona Sul, já que os responsáveis pelos estabelecimentos contatados demonstraram extrema preocupação com a privacidade dos clientes. Na região Norte, ao contrário, não se ouviu nas drogarias visitadas comentários sobre a obediência aos protocolos, nem grandes preocupações quanto à privacidade da clientela. A maior preocupação com a privacidade na Zona Sul é justificada pelos informantes pelo nível de informação e/ou escolaridade da clientela. Essa questão é importante de ser problematizada, especialmente porque no Brasil os medicamentos contraceptivos são adquiridos por suas usuárias principalmente nas drogarias e não nos serviços públicos de saúde (Cabral, 2011, p. 32).

Ressaltamos ainda que a substituição do uso do TCLE de modo formal pela técnica de passar mais tempo conversando e explicando um a um sobre os aspectos mais gerais da pesquisa resultou promissor, pois permitiu uma interação real e não intimidou os participantes no momento inicial com assinaturas de documentos. A experiência vivenciada fomenta a discussão a respeito da necessidade dos pesquisadores das ciências sociais e humanas, especialmente aqueles atuantes na área da saúde, problematizarem os modelos de pesquisas consagrados nas ciências naturais, em favor da incorporação de um arcabouço ético e metodológico mais amplo que oriente a prática de investigação, mas que ao mesmo tempo permita a criatividade e a construção de um processo empático pouco convencional entre investigadores e sujeitos pesquisados. Nas pesquisas antropológicas, a inclusão da subjetividade do pesquisador e sujeitos é a matéria-prima com a qual se confecciona a análise e interpretação dos dados coletados.

No decorrer do trabalho de campo, optou-se pela não continuidade da aplicação do questionário aos consumidores, devido ao fato dele ter sido concebido como um instrumento preliminar de aproximação com o campo. E não sendo utilizado em larga escala, seus resultados pouco acrescentariam à pesquisa. 
Assim, priorizou-se a observação da interação entre os/as consumidoras/es e balconistas no momento da venda da CE. Certamente, o pouco contato com os/ as consumidores/as da CE se deveu tanto ao próprio processo de estruturação do trabalho de campo que ocorreu dentro da drogaria quanto ao caminho escolhido para integração naquele espaço.

Percebeu-se que seria inviável a valorização, em igual medida, do olhar sobre quem está dentro e fora do balcão. Por isso, considerou-se mais viável e adequado aos objetivos priorizar o olhar sobre a drogaria, seus personagens, suas formas de organização, e como tais aspectos rebatem no atendimento realizado aos/às consumidores/as da "pílula do dia seguinte".

Finalmente, é fundamental observar que as identidades e diferenças e os papéis e posições assumidos pela pesquisadora e sujeitos pesquisados no início do trabalho de campo foram determinantes para o desenvolvimento desta etnografia. Em pesquisa social não temos fórmulas prontas para o estabelecimento desse relacionamento; por isso, o método e a ética estão interligados e dependem do exercício criativo e do julgamento do pesquisador e sujeitos investigados. A origem mineira da pesquisadora foi um fator de aproximação inicial importante. Chegar sem dar muitas explicações foi possível na realidade da Zona Norte. Ali não houve dificuldades de comunicação e integração, apesar do distanciamento e estranhamento inicial em relação ao universo sociocultural de que eles/elas faziam parte e com o qual se identificavam. Enfim, o trabalho de campo, com todos os seus imponderáveis, é o fascínio e o grande aprendizado deste árduo ofício.

\section{Agradecimentos}

Agradecemos a CAPES/CNPQ que financiou esta investigação e à equipe do projeto mais amplo, ao qual esta pesquisa está integrada: "Uma investigação socioantropológica no âmbito das farmácias/drogarias: posição de farmacêuticos e balconistas sobre a contracepção de emergência" (2012-2014)- apoio FAPERJ/CNPq, coordenado pela Profa. Dra. Elaine Reis Brandão. A equipe é composta por: Profa. Miriam Ventura (IESC-UFRJ); Profa. Cristiane da Silva Cabral (FSP-USP); Naira Vidal de Oliveira e Iolanda Szabo (FF-UFRJ); Sabrina Pereira Paiva (IESC-UFRJ) e Luiza Lena Bastos (IESC-UFRJ).

\section{Contribuição dos autores}

Paiva foi responsável pela elaboração do estudo, coleta, análise e interpretação dos dados e redação do artigo. Brandão foi responsável pela elaboração do estudo, análise e interpretação dos dados e revisão do artigo.

\section{Referências}

BASTOS, C. R. G.; CAETANO, R. As percepções dos farmacêuticos sobre seu trabalho nas farmácias comunitárias em uma região do estado do Rio de Janeiro. Ciência \& Saúde Coletiva, Rio de Janeiro, v. 15, n. 3, p. 3541-3550, 2010.

BERREMAN, G. D. Etnografia e controle de impressões em uma aldeia do Himalaia. In: GUIMARÃES, A. Z. Desvendando máscaras sociais. Rio de Janeiro: Francisco Alves, 1975. p. 123-174.

BOURDIEU, P. Introdução a uma sociologia reflexiva. In: O poder simbólico. Rio de Janeiro: Bertrand Brasil, 1989. p. 17-58.

BRASIL. Câmara dos Deputados. Lei n 5.991, de 17 de dezembro de 1973. Dispõe sobre o controle sanitário do comércio de drogas, medicamentos, insumos farmacêuticos e correlatos, e dá outras providências. Diário Oficial da União, Brasília, DF, 17 dez. 1973. Disponível em: <http://www2. camara.leg.br/legin/fed/lei/1970-1979/lei-5991-17dezembro-1973-358064-normaatualizada-pl.pdf>. Acesso em: 6 nov. 2011.

BRASIL. Ministério da Saúde. Conselho Nacional de Saúde. Comissão Nacional de Ética em Pesquisa (CONEP). Resolução no 196/1996. Normas para pesquisa envolvendo seres humanos. CNS, 1996. Disponível em: <http://www.dtr2oo4. saude.gov.br/susdeaz/legislacao/arquivo/ Resolucao_196_de_10_10_1996.pdf >>. Acesso em: 4 nov. 2012.

BRASIL. Ministério da Saúde. Resolução da Diretoria Colegiada (RDC) no 44 da Agência Nacional de Vigilância Sanitária, de 17 de agosto de 2009. Diário Oficial da União, Brasília, DF, 18 ago. 2009. Disponível em: <http://cfo.org.br/wpcontent/uploads/2010/02/180809_rdc_44.pdf>. Acesso em: 6 nov. 2011. 
BRASIL. Ministério da Saúde. Anticoncepção de emergência: perguntas e respostas para profissionais de saúde. 2. ed. Brasília, DF, 2011. Disponível em: <http://bvsms.saude.gov.br/ bvs/publicacoes/anticoncepcao_emergencia_ perguntas_respostas_2ed.pdf $>$. Acesso em: 4 nov. 2012.

BRASIL. Ministério da Saúde. Protocolo para utilização do levonorgestrel. Brasília, DF, 2012a. Disponível em: <http://bvsms.saude.gov.br/ bvs/publicacoes/protocolo_para_utilizacao_ levonorgestrel.pdf >. Acesso em: 18 jan. 2014.

BRASIL. Ministério da Saúde. Conselho Nacional de Saúde. Comissão Nacional de Ética em Pesquisa (CONEP). Resolução no 466, de 12 de dezembro de 2012b. Estabelece diretrizes e normas regulamentadoras de pesquisas envolvendo seres humanos. Diário Oficial da União, Brasília, 13 jun. 2013. Disponível em: <http://conselho.saude.gov. br/resolucoes/2012/Reso466.pdf >. Acesso em: 18 jan. 2014.

CABRAL, C. S. Práticas contraceptivas e gestão da heterossexualidade: agência individual, contextos relacionais e gênero. 2011. Tese (Doutorado em Saúde Coletiva) - Instituto de Medicina Social da Universidade do Estado do Rio de Janeiro, Rio de Janeiro, 2011.

CONRAD, P. The medicalization of society: on the transformation of human conditions into treatable disorders. Baltimore: JHU, 2007.

DINIZ, D.; MEDEIROS, M. Aborto no Brasil: uma pesquisa domiciliar com técnica de urna. Ciência \& Saúde Coletiva, Rio de Janeiro, v. 15, p. 959-966, 2010. Suplemento1.

DREZETT, J. Contracepção de emergência: normativas, usos, mitos e estigmas. In: ARILHA, M. et al. (Org.). Contracepção de emergência no Brasil e América Latina: dinâmicas políticas e direitos sexuais e reprodutivos. São Paulo: Oficina Editorial, 2010. p. 63-90.

DUARTE, L. F. D. Da vida nervosa nas classes trabalhadoras urbanas. Rio de Janeiro: Jorge Zahar: CNPq, 1986.
FAINZANG, S. L'automédication ou les mirages de l'autonomie. Paris: Presses Universitaires de France, 2012.

FARINA, S. S.; ROMANO-LIEBER, N. S. Atenção farmacêutica em farmácias e drogarias: existe um processo de mudança? Saúde e Sociedade, São Paulo, v. 18, n. 1, p.7-18, 2009.

FAVREET-SAADA, J. Ser afetado. Cadernos de Campo: Revista dos Alunos de Pós-Graduação em Antropologia Social da USP, São Paulo, ano 14, n. 13, p. 155-163, 2005.

FIGUEIREDO, R. et al. (Org.). Comportamento sexual, uso de preservativos e contracepção de emergência por adolescentes do município de São Paulo: estudo com estudantes de escolas públicas de ensino médio. São Paulo: Instituto de Saúde, 2008.

FOOTE-WHYTE, W. Treinando a observação participante. In: GUIMARÃES, A. Z. Desvendando máscaras sociais. 2. ed. Rio de Janeiro: Francisco Alves, 1975. p. 77-86.

GEERTZ, C. A interpretação das culturas. Rio de Janeiro: Guanabara Koogan, 1989.

GEERTZ, C. Obras e vidas: o antropólogo como autor. Rio de Janeiro: UFRJ, 2005.

GIUMBELLI, E. Para além do "trabalho de campo": reflexões supostamente malinowskianas. Revista Brasileira de Ciências Sociais, São Paulo, v. 17, n. 48, p. 91-107, 2002.

GUARIGLIA, F.; BENTO, S. F.; HARDY, E. Adolescentes como voluntários de pesquisa e consentimento livre e esclarecido: conhecimento e opinião de pesquisadores e jovens. Cadernos de Saúde Pública, Rio de Janeiro, v. 22, n. 1, p. 54-62, 2006.

HEILBORN, M. L. Corpos na cidade: sedução e sexualidade. In: VELHO, G. Antropologia urbana: cultura e sociedade no Brasil e em Portugal. Rio de Janeiro: Jorge Zahar, 1999. p. 93-102.

HEILBORN, M. L. Antropologia e saúde: considerações éticas e conciliação multidisciplinar. In: VÍCTORA, C. et al. (Org.). Antropologia e ética: o debate atual no Brasil. Niterói: EdUFF, 2004. p. 57-64. 
HOONAARD, W. C. V. D. A explosão da bolha: relações entre pesquisador e participantes pesquisados. In: GUERRIERO, I. et al. (Org.). Ética nas pesquisas em ciências humanas e sociais na saúde. São Paulo: Aderaldo \& Rothschild, 2008. p. 83-101.

KNAUTH, D. A etnografia na saúde coletiva: desafios e perspectivas. In: SCHUCH, P. et al. (Org.). Experiências, dilemas e desafios do fazer etnográfico contemporâneo. Porto Alegre: UFRGS, 2010. p. 109-114.

KUSCHNIR, K. Uma pesquisadora na metrópole: identidade e socialização no mundo da política. In: VELHO, G.; KUSCHNIR, K. (Org.). Pesquisas urbanas: desafios do trabalho antropológico. Rio de Janeiro: Jorge Zahar, 2003. p. 20-42.

LEUNG, V. W. Y.; SOON, J. A.; LEVINE, M. Mechanisms of action of hormonal emergency contraceptives: a literature review. Pharmacotherapy, Malden, v. 3o, n. 2, p. 158-168, 2010.

NASCIMENTO, M. C. do. Medicamentos, comunicação e cultura. Ciência \& Saúde Coletiva, Rio de Janeiro, v. 10, p. 179-193, 2005. Suplemento.

OLIVEIRA, A. B. et al. Obstáculos da atenção farmacêutica no Brasil. Revista Brasileira de Ciências Farmacêuticas, São Paulo, v. 41, n. 4, p. 409-412, 2005.

PAIVA, S. P.; BRANDÃO, E. R. Contracepção de emergência no contexto das drogarias: revisão crítica de literatura. Physis, Rio de Janeiro, v. 22, n. 1, p. 17-34, 2012.

PAIVA, S. P.; BRANDÃO, E. R. Conversas de balcão: notas etnográficas em uma drogaria. In: FLEISCHER, S.; FERREIRA, J. (Org.). Etnografias nos serviços de saúde. Rio de Janeiro: Garamond: FAPERJ, 2014. p. 181-208.

PARK, R. E. A cidade: sugestões para a investigação do comportamento no meio urbano. In: VELHO, O. (Org.). O fenômeno urbano. 4. ed. Rio de Janeiro: Jorge Zahar, 1979. p. 26-67.

Recebido: 17/03/2013

Reapresentado: 24/01/2014

Aprovado: 05/05/2014
RIO DE JANEIRO (município). Instituto

Pereira Passos. Censo Demográfico 2010. Rio de Janeiro, 2010. Disponível em: <http://www. armazemdedados.rio.rj.gov.br/>. Acesso em: 4 nov. 2012.

ROGERS, W.; BALLANTYNE, A. Populações especiais: vulnerabilidade e proteção. RECIIS Revista Eletrônica de Comunicação, Informação e Inovação em Saúde, Rio de Janeiro, v. 2, p. 31-41, 2008. Suplemento1.

ROSTAGNOL, S. Trabajo de campo en entornos diversos: reflexiones sobre las estrategias de conocimiento. Gazeta de Antropología, [S.l.], v. 27, n. 1, p. 1-14, 2011.

SARTI, C. A família como espelho: um estudo sobre a moral dos pobres. 3. ed. São Paulo: Cortez, 2005.

SCHMIDT, M. L. S. Aspectos éticos nas pesquisas qualitativas. In: GUERRIERO, I. et al. (Org.). Ética nas pesquisas em ciências humanas e sociais na saúde. São Paulo: Aderaldo \& Rothschild, 2008. p. 47-52.

SOUZA, R. A.; BRANDÃO, E. R. À sombra do aborto: o debate social sobre a anticoncepção de emergência na mídia impressa brasileira (20052009). Interface, Botucatu, v. 16, n. 40, p. 161-176, 2012.

VELHO, G. Individualismo e cultura: notas para uma antropologia da sociedade contemporânea. 8 . ed. Rio de Janeiro: Zahar, 2008.

VENTURA, M. Direitos reprodutivos no Brasil. 3 . ed., Brasília, DF: [s.n.], 2009.

WILLIAMS, S. J.; MARTIN, P.; GABE, J. The pharmaceuticalisation of society?: a framework for analysis. Sociology of Health \& Illness, [S.l.], v. 33, n. 1, p. 1-16, 2011.

WYNN, L. L.; FOSTER, A. M. The birth of a global reproductive health technology: an introduction to the Journey of Emergency Contraception. In: FOSTER, A. M.; WYNN, L. L. (Ed.). Emergency contraception: the story of a global reproductive health technology. New York: Palgrave Macmillan, 2012. p. 3-17. 